KNIGHT, B. C. J. G. (1955). J. gen. Microbiol. 12, 348-351

\title{
Nutritional Characters
}

\author{
By B. C. J. G. KNIGHT \\ Department of Microbiology, University of Reading
}

The purpose of this contribution is to suggest that at least certain of the nutritional requirements of micro-organisms are sufficiently stable and characteristic as to be of use in classification. This may at first seem surprising in view of the relative ease with which nutritionally exacting mutants can be obtained by the use of mutagenic agents. But there is evidence that under natural conditions and in normal laboratory maintenance on complex media (i.e. under conditions when more exacting mutants would not be selected) the nutritional requirements of micro-organisms defined on other grounds are often very characteristic. Although the easily testable nutritional requirements are perhaps not very numerous, yet sufficient variety exists to make the examination of nutritional requirements a useful method in classification. This conclusion may be illustrated by four examples.

(1) $m$-Inositol. This compound was one of the earliest growth factors to be isolated and chemically identified when it was found to be a growth factor required by certain yeasts (Eastcott, 1928). $m$-Inositol was subsequently found to be a nutrient required by other Eumycetes (others of which synthesize it). But there appears to be no authenticated report of $m$-inositol being a required nutrient among the Schizomycetes, although a few (all examined) have been shown to synthesize it (e.g. Thompson, 1942). Without further documentation it may be said summarily that $m$-inositol bears the character of an essential metabolite, i.e. a substance required in the growth of many different organisms and which, when it cannot be synthesized endogenously, becomes a nutrient requirement and must be supplied preformed. It is very surprising that no schizomycete which requires $m$-inositol as a nutrient has yet been reported, while this requirement has been observed fairly frequently among the Eumycetes. It might be argued that for some reason unknown a failure of inositol biosynthesis in a schizomycete is lethal and cannot be circumvented by the utilization of externally supplied $m$-inositol as it can in certain Eumycetes. When inositol-dependent mutants of Aerobacter aerogenes, which according to Thompson (1942) synthesizes $m$-inositol, were sought in screening experiments after treatment with mutagenic agents, none was found (Dr G. Pontecorvo; private communication). This supports the significance of the absence of reports of schizomycetes with nutritional requirements for $m$-inositol. There is thus some evidence that Eumycetes and Schizomycetes are different in their relation to $m$-inositol; a deficiency in biosynthesis of $m$-inositol can be circumvented by an external supply of it in Eumycetes, whereas such a deficiency either cannot arise in Schizomycetes without being lethal and is not remedied by externally supplied $m$-inositol, or $m$-inositol is 
not a general essential metabolite for these forms. In any case the distinction is interesting; it might reflect some phylogenetic difference. Whether the difference in relation to $m$-inositol can be correlated with some other character which separates these great subdivisions of the Thallophyta remains to be studied.

(2) In the genus Haemophilus are the classical organisms which exhibit nutritional requirements for one or both of the growth factors originally named, respectively, the $\mathbf{V}$ factor (now known to be one or other of the pyridine nucleotide co-enzymes or certain precursors) and $\mathrm{X}$ factor (certain porphins) as minimal nutrients. The designation of nutritional requirements as characteristic of these organisms is of surprisingly old standing (Kristensen, 1922; Fildes, 1923) and is used in Bergey's Manual (6th ed., 1948). Incidentally, an organism which was classified as $H$. duplex in the previous (5th) edition of Bergey's Manual (1939) was transferred to Moraxella as the species M. lacunata in the 6th (1948) edition largely on the evidence and arguments of Lwoff (1939) and Audureau (1940) who adduced nutritional requirements as part of the characterization in Moraxella. The removal of the moraxellas from the genus Haemophilus renders the nutritional characterization of this genus much more homogeneous. This process is carried still further by the study of Proom (1955) on the nutrition of strains of pertussis, parapertussis and bronchiseptica which 'supports the already impressive evidence that these groups should be classified separately'. Proom found that all the strains examined had a nutritional requirement for nicotinic acid and no other vitamin, and had other nutritional and physiological similarities. In all, the nutritional findings offer strong support to the proposal of López (1952) of a new genus Bordetella to include Bordetella pertussis, parapertussis and bronchiseptica.

(3) Athiorhodaceae. Van Niel (1944) made a very thorough study of the ecology, morphology and physiology of the photosynthesizing bacteria belonging to the family Athiorhodaceae and eventually recognized six welldefined species distributed in two genera. Subsequently, Hutner $(1946,1950)$ examined the nutrient requirements of van Niel's strains with respect to biotin, nicotinic acid, $p$-aminobenzoic acid and thiamine. Each van Niel species had a characteristic nutritional pattern, the intraspecific variation being remarkably small. For example, Rhodospirillum rubrum usually required biotin only, Rhodopseudomonas spheroides required biotin + thiamine + nicotinic acid, $R$. palustris required $p$-aminobenzoic acid (9 of 10 strains examined). The correlation between the other characters used to define species and the specific nutrient patterns is so close that strains could be assigned to species on nutritional pattern alone with little likelihood of error.

(4) The genus Bacillus. The differentiation of mesophilic species in this genus has been well worked out by Smith, Gordon \& Clark (1946, 1952). Their earlier (1946) classification was adopted in Bergey's Manual (6th ed., 1948). They divided the genus into three groups based on the morphology of the spores and sporangia. The subdivision into species and varieties was made upon physiological characteristics. In the 1946 monograph of Smith et al. there were fifteen species and seven varieties. This contrasted with the 
150 or so differently named cultures which they examined and the twenty-six pages in double column of unallocated and insufficiently described strains recorded in the appendix in Bergey's Manual (1948). Knight \& Proom (1950) collected about $\mathbf{3 0 0}$ fresh isolates of mesophilic Bacillus species from soil and classified them according to Smith et al. (1946). A good number of named laboratory strains was also collected and their characters checked in the same way (not all the names were substantiated). From this collection of fresh isolates and laboratory strains about 200 were examined for their nutritional requirements with regard to ammonia or amino acids and various growth factors (biotin, nicotinic acid, pantothenic acid, thiamine). Since the isolation of the strains from soil had taken place in nutritionally rich media it was reasonable to assume that no selection for simpler nutrient requirements had taken place and that the nutritional patterns of the fresh isolates did represent those of the organisms living in the soil. It was found, in general, that the nutritional patterns of new isolates of a species as defined by Smith et al. (1946) and the corresponding laboratory strains agreed very well. Thus the nutritional characters had survived what was in many cases longcontinued laboratory cultivation. This already indicated a certain stability of the nutritional patterns. What was perhaps more surprising was the finding that there was a close correlation between the patterns of morphological and physiological characters used by Smith, et al. (1946) to define their species, and the corresponding nutritional patterns. Within the collections of strains of the same species there was a surprising uniformity of nutritional pattern. The new species Bacillus pantothenticus described by Proom \& Knight (1950) was clearly characterized by its requirement for pantothenic acid-unique among the mesophilic Bacillus spp.--as well as by its morphology and other physiological characters. These specific nutritional patterns thus appeared to be highly characteristic of these species of Bacillus defined on quite other grounds, just as Hutner found with the Athiorhodaceae. Stanier (1953), in discussing this kind of finding with the Athiorhodaceae, said:

Since we know that a vitamin requirement can be brought about by a single gene-mutation, there was certainly no a priori reason for expecting that in a group where dependency on an exogenous vitamin has become the rule, the pattern of [nutritional] dependency should be so rigidly fixed for each species, particularly since the general ecology of the group, governed by its unique photosynthetic properties, is both narrow and uniform. One is forced to conclude that the special constellation of vitamin requirements which characterizes each species must possess great adaptive value, either direct or indirect, although the reason for this remains wholly obscure.

This outlook applies equally well to the nutrient requirements of the species of Bacillus. As Stanier further pointed out, even highly mutable single-gene characters '... may often be perfectly good taxonomic ones, if they possess adaptive value in a natural environment and are consequently maintained by selection?. In the case of Bacillus nutrition the comparison between fresh isolates and old laboratory strains did not suggest that the nutritional patterns were highly variable. The patterns of nutritional requirement shown, for 
example among the Bacillus species, reveal biosynthetic deficiencies. It should not be assumed that these deficiencies are due only to single-step biosynthetic defects or single-gene mutations or that the character could only be maintained by selection (see Stanier above). During the course of time multiple deficiencies in the same biosynthetic pathway may have accumulated which, alone, would render these nutritional patterns much more stable.

With the examples of Haemophilus, the Athiorhodaceae, Bordetella and Bacillus before us (and other examples could be adduced) it appears that there is now ample evidence to suggest that the nutritional patterns of microbial species may be among the properties always well worth considering as characters to use in classification.

\section{REFERENCES}

Audureau, A. (1940). Étude du genre Moraxella. Ann. Inst. Pasteur, 64, 126.

Bergey's Manual of Determinative Bacteriology (1939). 5th ed. Edited by Bergey, D. H., Breed, R. S., Murray, E. G. D. \& Hitchens, A. P. Baltimore: The Williams and Wilkins Co.

Bergey's Manual of Determinative Bacteriology (1948). 6th ed. Edited by BreED, R. S., Murray, E. G. D. \& Hrtchens, A. P. London: Baillière, Tindall and Cox.

EAstcotr, E. V. (1928). Wildier's bios. The isolation and identification of Bios I. J. phys. Chem. 32, 1094.

Fildes, P. (1923). The classification of haemoglobinophilic bacteria based upon their relation to blood pigment and to the vitamin factor. Brit. J. exp. Path. 4, 265.

Hutner, S. H. (1946). Organic growth essentials of the aerobic non-sulphur photosynthetic bacteria. J. Bact. 52, 213.

HutNer, S. H. (1950). Aerobic and anaerobic growth of purple bacteria (Athiorhodaceae) in chemically defined media. J. gen. Microbiol. 4, 286.

KNIGHT, B. C. J. G. \& Proom, H. (1950). A comparative survey of the nutrition and physiology of mesophilic species in the genus Bacillus. J. gen. Microbiol. 4, 508.

Kristensen, M. (1922). Investigations into the Occurrence and Classification of the Haemoglobinophilic Bacteria. Copenhagen: Levin and Munksgaard.

LóPEz, M. M. (1952). El genero Bordetella. Microbiol. esp. 5, 177.

Lwoff, A. (1934). Revision et démembrement des Hemophilae; le genre Moraxella nov.gen. Ann. Inst. Pasteur, 62, 168.

vaN Nies, C. B. (1944). The culture, general physiology, morphology and classification of the non-sulphur purple and brown bacteria. Bact. Rev. 8, 1.

Proom, H. (1955). The minimal nutritional requirements of organisms of the genus Bordetella Lopez. J. gen. Microbiol. 12, 63.

Proom, H. \& Knight, B. C. J. G. (1950). Bacillus pantothenticus n.sp. J. gen. Microbiol. 4, 539.

Smith, N. R., Gordon, R. E. \& Clark, F. E. (1946). Aerobic mesophilic sporeforming bacteria. Misc. Publ. U.S. Dep. Agric. no. 559.

Smith, N. R., Gordon, R. E. \& Clark, F. E. (1952). Aerobic spore-forming bacteria. U.S. Dep. Agric., monograph no. 16.

Stanier, R. Y. (1953). Adaptation, evolutionary and physiological: or Darwinism among the micro-organisms. In Adaptation in Micro-organisms. Symp. Soc. gen. Microbiol. 3, 1.

Thompson, R. C. (1942). Studies on the vitamin content of tissues. II. Univ. Tex. Publ. no. 4237, p. 87. 